\title{
Defect Microstructure in Irradiated Silicon Carbide
}

\author{
Sosuke Kondo ${ }^{1}$, Yutai Katoh ${ }^{2}$, Lance L. Snead ${ }^{2}$, Tatsuya Hinoki ${ }^{1}$
}

1. Institute of Advanced Energy, Kyoto University, Uji, Japan.

2. Materials Science and Technology Division, Oak Ridge National Laboratory, Oak Ridge, USA.

Recent interest in silicon carbide ( $\mathrm{SiC})$ and its composites ( $\mathrm{SiC} / \mathrm{SiC}$ composites) has been motivated historically by its possible utilization as a structural and functional material in fusion blankets in 1970s [1]. They are now attracting attention as alternative materials for fuel cladding for operating fission reactors (LWR) because of the conceivable better chemical stability and strength under LOCA or beyond design basis conditions in addition to the fusion and gas cooled reactors [2]. The advantages include perceived radiation stability at temperatures $<1000{ }^{\circ} \mathrm{C}$ that comes from retention of radiation produced nano-structured defects up to high fluences. The knowledge regarding the microstructural change in $\mathrm{SiC}$ during irradiation has thus far been mainly limited to the low-to-intermediate temperature regime, and has hampered the determination of upper temperature and fluence limits for the severe use conditions now being considered. Important rapid property changes are anticipated at very high temperatures, where irradiation induced microstructural defects undergo unstable growth. This paper will review our recent results on the evolutions of dislocation and void microstructures in ion- or neutron-irradiated $\beta$-SiC, especially for the high temperatures beyond the upper service temperature limits for metallic heat resistant structural alloys. Some of advanced techniques on the defect analysis will also be touched on.

The literature offers only limited microstructural information on $\beta$-SiC subjected to high temperature neutron irradiation until late 1990. Price (1973) first observed irradiation induced void formation in $\mathrm{SiC}$ deposited on graphite discs, the irradiation condition of void formation was neutron fluence of $4.3 \times 10^{25}$ $\mathrm{n} / \mathrm{m}^{2}(\mathrm{E}>0.18 \mathrm{MeV})$ and an irradiation temperature of $1250{ }^{\circ} \mathrm{C}$ or higher [3]. Price (1969) and Blackstone (1971) et al. reported macroscopic volumetric expansion in neutron irradiated $\mathrm{SiC}$ at high temperatures $\left(\sim 1500^{\circ} \mathrm{C}\right)[5]$. No information on the relation between microstructure and macroscopic length change in irradiated $\beta$-SiC, however, has been available until not long ago. Several self-ion irradiation experiments also reported cavity formation in $\mathrm{SiC}$, where cavities were observed at $>1000{ }^{\circ} \mathrm{C}$ [4]. Recently, Snead et al. reported the temperature and fluence dependent swelling in very high purity $\mathrm{SiC}$ (produced through chemical vapor deposition (CVD)) in the high temperature regime [6], and formation of voids was considered the probable cause of the swelling. Our work clarified that cavities were predominantly spherical in shape below $1300^{\circ} \mathrm{C}$. Additional voids faceted with $\{111\}$ planes were dominating at $1460{ }^{\circ} \mathrm{C}$, which were basically tetrahedral truncated at the corners with $\{111\}$. The tetrahedral shape was unexpected as the surface-to-volume ratio is larger than the alternative $\{111\}$ octahedral void common in both metals and ceramics. From a geometric viewpoint, all faces of the observed voids are either Si- or C-terminated surfaces. By comparing the surface area with the octahedral void (composed of the both $\mathrm{Si}$ - and $\mathrm{C}$-surfaces) of the same volume, the considerable difference in surface energy between the $\mathrm{Si}(111)$ and $\mathrm{C}(-1-1-1)$ was implicated [7]. One can conclude now that those are responsible for the high temperature swelling in $\mathrm{SiC}$.

Other microstructural features in neutron-irradiated $\mathrm{SiC}$ are black spot defects and/or small dislocation loops $(\mathrm{r} \sim 3 \mathrm{~nm})$ after irradiation at relatively low fluences between 300 and $1100{ }^{\circ} \mathrm{C}$. The small dislocation loops were identified as lying on $\{111\}$ lattice planes, and have been tentatively identified as Frank loops without Burgers vector analysis. Recently, Katoh et al. (2006) suggested that these were a 
mixture of Frank loops and other type defect clusters, for example having Burgers vector of Shockley partial, by means of Burgers vector analysis for CVD SiC irradiated to $7.7 \times 10^{25} \mathrm{n} / \mathrm{m}^{2}(\mathrm{E}>0.1 \mathrm{MeV})$ at $800^{\circ} \mathrm{C}$. No evidence was reported because of their small size, but these defects were believed to be interstitial type based on difference in the mobilities of interstitials and vacancies in SiC. A highresolution electron microscope image of a relatively larger planner defect on (111) in heavy-neutron irradiated $\mathrm{SiC}$ has been estimated to be an interstitial-type Frank loop by image simulation [8]. In our work, large dislocation loops were identified as interstitial-type, a0/3<111 $>$ Frank loops using the inside/outside contrast method. It would appear that small loops at $1130{ }^{\circ} \mathrm{C}$ were also Frank loops: at least we confirmed the habit plane was $\{111\}$ and their Burgers vector was parallel to $<111>$.

In order to obtain the information about the interstitial motion in $\mathrm{SiC}$, the temperature-dependent width of the interstitial loop denuded zone (DZ) formed along the random grain boundaries was evaluated [10]. The quantitative analysis showed a positive temperature dependence of the DZ width, where the smallest DZ width of $8.9 \mathrm{~nm}$ was observed in $\mathrm{SiC}$ irradiated at $1010{ }^{\circ} \mathrm{C}$ and the largest of $57 \mathrm{~nm}$ was observed at $1380{ }^{\circ} \mathrm{C}$. Significant populations of small TEM invisible voids $\left(\mathrm{r}_{v}=0.2-0.7 \mathrm{~nm}\right)$ were theoretically found to be formed in specimens irradiated below $1130{ }^{\circ} \mathrm{C}$ based on a simple reactiondiffusion equation, which were supposed to be limiting the interstitial motion at lower temperatures. The temperature-dependent diffusion coefficient estimated from the loop-denuded width showed an activation energy of interstitial migration of $1.5 \pm 0.1 \mathrm{eV}$ in $\mathrm{SiC}$, which is likely associated with the slower-moving species of Si interstitials. Finally, we concluded that the excellent irradiation stability of $\mathrm{SiC}$ is attributed to its stable microstructural defects due to the very high sink strength of vacancies even at high temperature and fluence. Advanced analytical technique in an electron microscopy may be best for understanding the ceramic specific features of the irradiation defects in a covalent bonding SiC, such as the stoichiometry constraint of the loops and the being of charged defects.

\section{References:}

[1] R.E. Riley, T.C. Wallace, J.M. Dickinson, J. Nucl. Mater. 85\&86 (1979) 221-224.

[2] S.J. Zinkle, K.A. Terrani, J.C. Gehin, L.J. Ott, L.L. Snead, “Accident tolerant fuels for LWRs: A perspective," J. Nucl. Mater., 448, 374-9 (2014).

[3] R.J. Price, J. Nucl. Mater. 48 (1973) 47-57.

[4] S. Kondo, T. Hinoki, A. Kohyama, Mater. Trans. 46 (2005) 1923-1927.

[5] R.J. Price, J. Nucl. Mater. 33 (1969) 17-22.

[6] L.L. Snead, T. Nozawa, Y. Katoh, T.S. Byun, S. Kondo, D.A. Petti, J. Nucl. Mater. 371 (2007) 329377.

[7] S. Kondo, L.L. Snead, Y. Katoh, Appl. Phys. Lett. 93 (2008) 163110.

[8] T. Yano, H. Miyazaki, M. Akiyoshi, T. Iseki, J. Nucl. Mater. 253 (1998) 78-86.

[9] Y. Katoh, N. Hashimoto, S. Kondo, L.L. Snead and A. Kohyama, J. Nucl. Mater. 351 (2006) 228240.

[10] S. Kondo, L.L. Snead, Y. Katoh, Phys. Rev. B 83, 075202 (2011) 